\title{
Removing competitive foods $v$. nudging and marketing school meals: a pilot study in high-school cafeterias
}

\author{
Rebecca Boehm ${ }^{1}$, Margaret Read ${ }^{2} \dagger$, Kathryn E Henderson $3, \dagger$ and \\ Marlene B Schwartz ${ }^{2, *, \dagger}$ \\ ${ }^{1}$ Food and Environment Program, Union of Concerned Scientists, Washington, DC, USA: ${ }^{2}$ UConn Rudd Center for \\ Food Policy and Obesity, 1 Constitution Plaza, Suite 600, Hartford, CT 06103, USA: ${ }^{3}$ Henderson Consulting, \\ Duncan, British Columbia, Canada
}

Submitted 7 January 2019: Final revision received 26 June 2019: Accepted 19 July 2019: First published online 3 December 2019

\begin{abstract}
Objective: To compare federally reimbursable school meals served when competitive foods are removed and when marketing and nudging strategies are used in school cafeterias operating the National School Lunch Program (NSLP). The second objective was to determine how marketing and nudging strategies influence competitive food sales.

Design: In the Healthy Choices School, all competitive foods were removed; the Healthy Nudging School retained competitive foods and promoted the school meal programme using marketing and nudging strategies; a third school made no changes. Cafeteria register data were collected from the beginning of the 2013-2014 school year through the four-week intervention. Outcome measures included daily entrées served; share of entrées served with vegetables, fruit and milk; and total competitive food sales. Difference-in-difference models were used to examine outcome measure changes.

Setting: Three high schools in a diverse, Northeast US urban district with universally free meals.

Participants: High-school students participating in the NSLP.

Results: During the intervention weeks, the average number of entrées served daily was significantly higher in the Healthy Choices School (82.1 (sE 33.9)) and the Healthy Nudging School (107.4 (SE 28.2)) compared with the control school. The only significant change in meal component selection was a $6 \%$ (se 0.02) higher rate of vegetable servings in the Healthy Choices School compared with the control school. Healthy Nudging School competitive food sales did not change.

Conclusions: Both strategies - removing competitive foods and marketing and nudging - may increase school meal participation. There was no evidence that promoting school meals decreased competitive food sales.
\end{abstract}

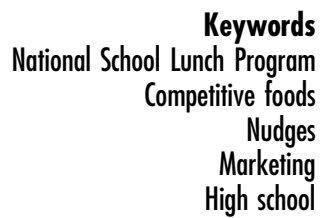

The National School Lunch Program (NSLP) is a vital resource for US children, especially those from low-income families. Today the programme serves over 30 million children daily ${ }^{(1)}$. The NSLP is the cornerstone of the school food environment; through federally mandated nutrition standards, the programme provides school-aged children in the USA with essential nutrients to nourish their growth and development. The Healthy, Hunger-Free Kids Act of 2010 (HHFKA) directed the US Department of Agriculture

†These authors were affiliated with Yale University when the intervention for the study was carried out. to update the nutrition standards for school meals, which led to encouraging improvements in the nutritional quality of student selected meals ${ }^{(2)}$. The HHFKA also required updated nutrition standards for competitive foods sold outside the reimbursable meal programme ${ }^{(3)}$. These nutrition standards, known as 'Smart Snacks', have led companies to reformulate products to sell in schools to meet fat, sugar, sodium and energy limits ${ }^{(4,5)}$.

Although Smart Snacks are healthier versions of competitive foods, the school lunch must still compete, albeit with baked chips, low-fat cookies and entrée-style items such as chicken nuggets. This has heightened a debate 
in the nutrition field about how to reduce consumption of competitive foods without adverse effects on student participation in school meal programmes ${ }^{(6,7)}$. Supporters of completely removing competitive foods argue that it is difficult for school meals to compete with heavily marketed items, and children will eventually accept healthier choices as they grow accustomed to them ${ }^{(8)}$. On the other hand, supporters of behavioural economics approaches in the lunchroom advise against completely removing unhealthy snacks, arguing that restricting choices leads to reactance (i.e. an increased desire for the forbidden foods and refusal of the healthy foods) ${ }^{(9)}$. Instead, behavioural economic and marketing strategies are recommended to nudge children away from less healthy foods and towards better choices $^{(10-14)}$

Published research on competitive foods in schools prior to HHFKA changes supported the feasibility and positive impact of substituting healthier snacks for less healthy snacks. One study conducted in six middle schools found that when school snacks were healthier, student consumption of less healthy snacks and beverages at school decreased, and there was not a compensatory increase in consumption of unhealthy snacks at home. Other studies have examined whether replacing traditional competitive foods with healthier snacks decreases participation in the school meal programme, and the findings consistently indicate that it does not ${ }^{(15-18)}$. Few studies have examined how completely removing all competitive foods impacts school meal participation ${ }^{(19)}$.

Research on how high-school students react to changes in competitive food standards and restrictions is particularly limited. It is important to study this age group because there are typically more competitive foods in high schools than in elementary and middle schools ${ }^{(20)}$. Strong competitive food policies can be challenging to implement in high schools because some argue that adolescents need practice negotiating the environment and learning how to make healthy choices in the 'real world'(21). An alternative view is that it is even more important to improve the school nutrition environment for older children because school meal participation and diet quality decline with age ${ }^{(20,22,23)}$.

The primary research question of the present study was: does removal of competitive foods from the school cafeteria increase utilization of the school meal programme? The hypothesis was that meal participation and student selection of meal components such as fruit, vegetables and milk would increase when competitive foods were not available. A second research question was: do marketing and nudging strategies to promote the school meal programme increase meal participation, increase meal component selection and reduce student purchases of competitive foods? The hypothesis was that these strategies would increase school meal participation, increase meal component selection and reduce purchases of competitive foods.

\section{Methods}

\section{Setting}

The study was conducted in a medium-sized urban school district in the Northeast USA during the 2013-2014 school year. All schools offered school lunch in compliance with federal standards and all three schools were closed campus, meaning students were not allowed to leave campus for the lunch period. During the year of data collection, the HHFKA school meal regulations were in place, but national Smart Snacks standards had not yet been implemented. The competitive foods sold in this district met state nutrition standards, which were almost identical to those in HHFKA ${ }^{(24)}$. Therefore, the snacks sold during the time of the study were consistent with Smart Snacks standards. The à la carte window during the lunch period was the only place students could purchase foods on each campus. There were no vending machines or other school stores at any of the schools enrolled in the study.

The school district population was racially and ethnically diverse ( $42 \%$ Black, $40 \%$ Hispanic, $2 \%$ Asian, 0.08\% Native American, 3\% multiracial, 13\% non-Hispanic White). Students were predominantly low-income, with free and reduced-price eligibility rate of $84-100 \%$ in the district high schools. The free and reduced-price school meal eligibility rate was $>95 \%$ for all three schools in the study and the school district provided free school meals to all students through the US Department of Agriculture Community Eligibility Provision ${ }^{(25)}$. The percentage of students with disabilities and the racial and ethnic composition at the three schools in the study were also assessed. No other information about school demographic characteristics was available on the state's Department of Education website. Menus were created at the district level and the reimbursable menu items were the same in all three high schools each day. The same competitive foods were available for procurement by cafeteria managers in all high schools.

Three high schools in the district were recruited for the study and were assigned to one of the three conditions. The research protocol was deemed exempt by the Yale University Institutional Review Board since there were no human subjects and all of the outcome data were administrative data from cafeteria registers (i.e. reimbursable meal counts, meal components and competitive food sales). The data were provided by the district food-service director with permission from district administrators.

\section{Procedure}

Baseline sales data were collected from September through mid-April of school year 2013-2014. The structural changes to the cafeteria and marketing materials were installed during the April spring break and data were collected for the four weeks following the spring break. The intervention in the Healthy Choices School was removing all competitive 
foods from the cafeteria. School food-service staff decided to use the former competitive food line to serve the cold lunch options that had been available all year in the NSLP lunch lines. These included pre-made sandwiches and salads. These cold lunch options were also available all year in the Comparison School and the Healthy Nudging School.

In the Healthy Nudging School, a collection of marketing and nudging (sometimes known as 'Smarter Lunchroom') interventions $^{(26)}$ was implemented when the students returned from spring break to promote the school lunch and encourage fruit and milk selection. The strategies included: placing fruit and milk in high-traffic areas and near cash registers; displaying whole fruit in colourful ceramic bowls; serving pre-cut fruit in grab-and-go containers; displaying posters of celebrities and athletes drinking milk; and highlighting the meal of the day in new signage. There were no changes to the availability of competitive foods. The Comparison School made no changes.

The research team monitored the implementation of the interventions in the Healthy Choices and Healthy Nudging Schools weekly to ensure schools conformed to study protocol. At the end of the intervention, data were obtained from all school cafeteria registers. The data included 332 school days across the three schools (282 baseline days; fifty intervention days).

\section{Measures}

Main outcome measures included: number of federally reimbursable school meal entrées served daily; number of cold and hot entrées served daily; the share of meals containing a vegetable, fruit or milk (including $1 \%$ white milk and skimmed flavoured milk); and total daily sales of competitive foods. Although cafeteria managers at all three schools could order the same competitive foods during 2013-2014 school year, there was some variability in item availability across schools. First, pretzel availability was inconsistent. The Healthy Nudging and Healthy Choices Schools had zero pretzel sales during the school year, while the Comparison School reported pretzel sales for twentyone of thirty-four weeks, including during the four-week intervention. Because our hypothesis was that competitive food sales would be higher in the Comparison School, pretzels were removed from all analyses to be conservative. Second, mozzarella sticks and ice cream sales were reported on limited days during the school year (i.e. fewer than three weeks) at only the Comparison and Healthy Nudging Schools. It was assumed that these items were sold only for special school events, so they were also excluded from the analysis. Supplemental Tables S1 and S2 in the online supplementary material list the entrée types served and the competitive foods sold at each school in the study.

\section{Data analysis strategy}

A difference-in-difference (DID) model was used to determine how the intervention influenced levels of all outcome measures. DID is well suited for evaluating policy changes or intervention effectiveness in observational studies where all background factors cannot be completely controlled $^{(27)}$. Using this method, the DID estimator is calculated as the average difference in outcome measures between the baseline and intervention period, minus the average difference in outcome measures between the intervention and comparison schools.

There are two main assumptions underlying the use of DID. First, the parallel trends assumption must be met. This means that trends in outcome measures prior to the beginning of the intervention across the comparison and intervention groups must be the same. Formal parallel trends testing was conducted for all outcome measures to confirm that this assumption was met. Second, the common shocks assumption requires that any unexpected events affect all schools in the study equally. Because these schools are located in the same city and school district, it is reasonable to assume that any factor that would influence the school meal programme (e.g. food supplier changes) would affect all three schools equally ${ }^{(28)}$.

Some school days were removed from the analysis sample using a multistage approach. First, for each individual school, days were removed if the number of entrées served fell below 2 SD of the mean, as these days were not representative of typical school meal participation. Nine days were removed by this method, and there was no association between the number of days removed and school $\left(\chi^{2}=0 \cdot 12, P=0.94\right)$. Next, five school days during January 2014 either ended early or were cancelled due to snowstorms, so these days were removed. Third, the school district calendar for school year 2013-2014 was reviewed to determine if there were shortened school days that would impact school meal service. Eleven days that were identified as professional development days or parent teacher conference days were removed.

Average daily values of all outcome measures were calculated to descriptively show how they varied between the intervention and comparison schools, and at baseline and during the intervention. The DID model was estimated using multiple linear regression, with one equation per outcome measure and separate equations for assessing the Healthy Choices School and Healthy Nudging School interventions. Each outcome measure was a separate dependent variable in these models. In all models, the DID estimator was an independent variable of the interaction between a binary variable indicating if the intervention was present at a school $(=1$ if the school was either the Healthy Choices School or Healthy Nudging School; $=0$ otherwise) and a binary variable indicating the time period of the study (=1 during the four-week intervention period; $=0$ if before the intervention). In all models, a month fixed effect was used to capture seasonal variation in school meal participation. Binary independent variables indicating the type of entrée served each day (there were thirty-seven distinct entrée types served across the 
three schools) were also included in the linear regression models.

The DID estimator was calculated as the difference in average daily value of the outcome measure between the baseline and intervention period, minus the difference in the average daily value of the outcome measures between the intervention and comparison schools, adjusted for independent covariates. A positive DID estimator indicates that the intervention increased the average daily value of the outcome measure and a negative estimator indicates that the intervention decreased the average daily value of the outcome measure $^{(27)}$. However, to compute unbiased DID estimators requires that trends in outcome measures for the control and intervention schools be equal during the baseline period ${ }^{(27)}$. Consequently, prior to the DID estimation we conducted a parallel trends assumption test for differences in trends across all outcome measures in the baseline period. All data analyses were conducted in the statistical software package Stata/SE version 15.1 .

\section{Results}

Table 1 shows total enrolment, the percentage of students by racial and ethnic groups, the percentage of students with a language other than English as their primary home language and the percentage of students who have a disability for the three schools in the sample ${ }^{(29)}$. There were no significant differences in these characteristics across the three schools, except for the percentage of students with a disability. There were significantly fewer students with a disability at the Comparison School.

The parallel trends assumption tests (Table 2 ) confirmed that none of the outcome measure time trends were statistically different when comparing the intervention schools with the Comparison School, thus satisfying this assumption for the use of DID.
Table 3 reports the average number of entrées served daily; the average share of those entrées served with a vegetable, fruit and milk; and the average competitive items sold daily at baseline and during the intervention at all three schools. These data were examined only descriptively, so no statistical tests were used to make comparisons. In both the baseline and intervention periods, the Comparison School served more entrées (both hot and cold) compared with the Healthy Choices School and the Healthy Nudging School. The Comparison School also sold more competitive foods than did the Healthy Nudging School in both periods. The Healthy Nudging School served more meals with vegetable sides compared with the Comparison and Healthy Choices Schools. The Healthy Choices School served fewer school meals with fruit and milk compared with the Healthy Nudging and Comparison Schools.

Estimated DID values for all outcome measures are reported in Table 4 . The number of daily entrées served was significantly higher in the Healthy Choices and Healthy Nudging Schools during the intervention period relative to the Comparison School. In the Healthy Nudging School, the average number of daily hot and cold entrées were both significantly higher during the intervention period. In the Healthy Choices School, the average number of cold entrées served as well as the proportion of entrées served with vegetables were significantly higher during the intervention compared with the Comparison School. In the Healthy Nudging School, there were no significant changes in meal component selection or total number of competitive foods sold.

\section{Discussion}

The primary research question of the present study was whether removing all competitive foods from a high-school cafeteria would increase meal participation and increase

Table 1 Racial and ethnic composition and primary home language spoken among students in three Northeast US urban high schools participating in a four-week study to assess two interventions (Healthy Choices and Healthy Nudging) to increase meal participation in high schools where all students in all three schools were eligible for free/reduced-price school meals under the US Department of Agriculture Community Eligibility Provision

\begin{tabular}{lccccc}
\hline & $\begin{array}{c}\text { Healthy } \\
\text { Choices } \\
\text { School } \\
(n 1177)\end{array}$ & $\begin{array}{c}\text { Healthy } \\
\text { Nudging } \\
\text { School } \\
(n 2140)\end{array}$ & $\begin{array}{c}\text { Comparison } \\
\text { School } \\
(n 1297)\end{array}$ & Pearson $\chi^{2}$ & $P$ value \\
\hline Race/ethnicity (\%) & & & & & \\
$\quad$ Non-Hispanic White & 5.9 & 11.4 & 5.9 & 5.89 & 0.436 \\
Black & 44.6 & 44.5 & 41.5 & & \\
Hispanic & 44.9 & 39.4 & 51.7 & & \\
Other race† & 0.8 & 1.3 & 0.4 & & \\
$\quad$ Asian & 3.8 & 3.4 & 0.5 & 1.69 & 0.430 \\
Students from non-English home & 42.8 & 42.8 & 40.5 & 15.0 & 0.001 \\
$\quad$ language (\%) & 17.9 & 16.4 & 12.5 & 15.0 \\
Students with disabilities (\%) & & & & & \\
\hline
\end{tabular}

†Other race includes American Indian or Pacific Islander students and students who reported being two or more races. 


\section{NŚ Public Ceath Nurrion}

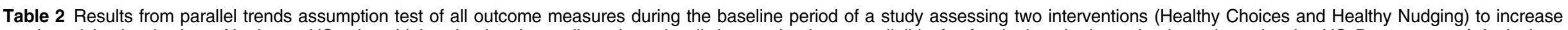

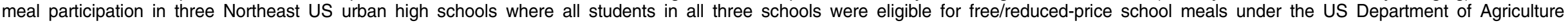
Community Eligibility Provision

\begin{tabular}{|c|c|c|c|c|c|c|c|c|c|c|c|c|c|c|}
\hline & \multicolumn{14}{|c|}{ Time trends for } \\
\hline & $\begin{array}{c}\text { Average } \\
\text { number of } \\
\text { daily } \\
\text { entrées } \\
\text { served }\end{array}$ & $95 \% \mathrm{Cl}$ & $\begin{array}{c}\text { Average } \\
\text { number of } \\
\text { daily cold } \\
\text { entrées } \\
\text { served }\end{array}$ & $95 \% \mathrm{Cl}$ & $\begin{array}{l}\text { Average } \\
\text { number of } \\
\text { daily hot } \\
\text { entrées } \\
\text { served }\end{array}$ & $95 \% \mathrm{Cl}$ & $\begin{array}{c}\text { Average } \\
\text { share of } \\
\text { entrées } \\
\text { served with a } \\
\text { vegetable } \\
\text { daily }\end{array}$ & $95 \% \mathrm{Cl}$ & $\begin{array}{l}\text { Average } \\
\text { share of } \\
\text { entrées } \\
\text { served } \\
\text { with a } \\
\text { fruit daily }\end{array}$ & $95 \% \mathrm{Cl}$ & $\begin{array}{l}\text { Average } \\
\text { share } \\
\text { entrées } \\
\text { served } \\
\text { with a } \\
\text { milk daily }\end{array}$ & $95 \% \mathrm{Cl}$ & $\begin{array}{l}\text { Average } \\
\text { number of } \\
\text { competitive } \\
\text { foods } \\
\text { sold daily }\end{array}$ & $95 \% \mathrm{Cl}$ \\
\hline Healthy Nudging School & $-0.262^{\star \star \star}$ & $-0.404,-0.119$ & -0.027 & $-0.135,0.081$ & $-0.219^{\star \star \star}$ & $-0.350,-0.088$ & $-0.001^{\star \star \star}$ & $-0.001,-0.000$ & -0.000 & $-0.000,0.000$ & $-0.000^{\star \star \star}$ & $-0.001,-0.000$ & -0.406 & $-0.588,-0.224$ \\
\hline Healthy Choices School & $-0.282^{\star \star \star}$ & $-0.424,-0.140$ & -0.031 & $-0.139,0.077$ & $-0.235^{\star \star \star}$ & $-0.366,-0.104$ & $-0.001^{\star \star \star}$ & $-0.001,-0.000$ & -0.000 & $-0.000,0.000$ & $-0.000^{\star \star \star}$ & $-0.001,-0.000$ & $-\dagger$ & - \\
\hline Comparison School & $-0 \cdot 286^{\star \star \star}$ & $-0.428,-0.144$ & -0.032 & $-0.140,0.076$ & $-0 \cdot 237^{\star \star \star}$ & $-0.368,-0.107$ & $\begin{array}{l}-0.001 * \star \\
282\end{array}$ & $-0.001,-0.000$ & $\begin{array}{l}-0.000 \\
282\end{array}$ & $-0.000,0.000$ & $\begin{array}{l}-0.000^{\star \star \star *} \\
282\end{array}$ & $-0.001,-0.000$ & -0.420 & $-0.602,-0.239$ \\
\hline $\begin{array}{l}\text { Number of days } \\
F \text { statistic }\end{array}$ & $\begin{array}{r}282 \\
915.52\end{array}$ & & $\begin{array}{r}282 \\
66.51\end{array}$ & & $\begin{array}{r}282 \\
665 \cdot 90\end{array}$ & & $\begin{array}{r}282 \\
42.73\end{array}$ & & $\begin{array}{r}282 \\
29.59\end{array}$ & & 282 & & $\begin{array}{r}192 \\
20617\end{array}$ & \\
\hline$P$ value & $<0.0001$ & & $<0.0001$ & & $<0.0001$ & & $<0.0001$ & & $\begin{array}{l}29.59 \\
<0.0001\end{array}$ & & $\begin{array}{l}31.98 \\
<0.0001\end{array}$ & & $\begin{array}{l}386.17 \\
<0.0001\end{array}$ & \\
\hline$R^{2}$ & 0.908 & & 0.418 & & 0.878 & & 0.316 & & 0.242 & & 0.257 & & 0.803 & \\
\hline
\end{tabular}

Data presented are regression coefficients with $95 \%$ confidence intervals. Regression constant coefficients are omitted from the table, but all were significant at $P<0.05$. Coefficient representing time trend in variable is statistically different from zero: ${ }^{* \star} P<0.001$.

tCompetitive foods were removed from the Healthy Choices School, so parallel trends test not conducted on competitive food sales for this school.

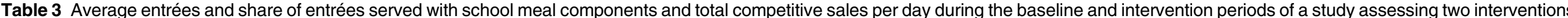

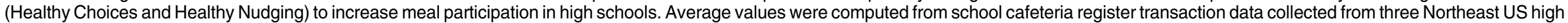

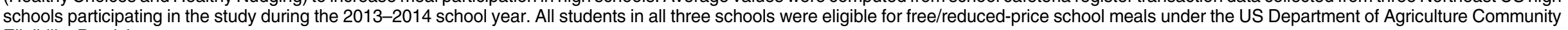
Eligibility Provision

\begin{tabular}{|c|c|c|c|c|c|c|c|c|c|c|c|c|c|c|c|}
\hline & & $\begin{array}{c}\text { Average } \\
\text { number } \\
\text { of daily } \\
\text { entrées } \\
\text { served }\end{array}$ & $95 \% \mathrm{Cl}$ & $\begin{array}{c}\text { Average } \\
\text { number } \\
\text { of daily } \\
\text { cold } \\
\text { entrées } \\
\text { served }\end{array}$ & $95 \% \mathrm{Cl}$ & $\begin{array}{c}\text { Average } \\
\text { number } \\
\text { of daily } \\
\text { hot } \\
\text { entrées } \\
\text { served }\end{array}$ & $95 \mathrm{Cl}$ & $\begin{array}{c}\text { Average } \\
\text { share of } \\
\text { entrées } \\
\text { served } \\
\text { with a } \\
\text { vegetable } \\
\text { daily }\end{array}$ & $95 \% \mathrm{Cl}$ & $\begin{array}{c}\text { Average } \\
\text { share of } \\
\text { entrées } \\
\text { served } \\
\text { with a } \\
\text { fruit daily }\end{array}$ & $95 \% \mathrm{Cl}$ & $\begin{array}{c}\text { Average } \\
\text { share } \\
\text { entrées } \\
\text { served } \\
\text { with a } \\
\text { milk } \\
\text { daily }\end{array}$ & $95 \% \mathrm{Cl}$ & $\begin{array}{l}\text { Average } \\
\text { number of } \\
\text { competitive } \\
\text { foods } \\
\text { sold daily }\end{array}$ & $95 \% \mathrm{Cl}$ \\
\hline \multirow[t]{2}{*}{ Comparison School } & Baseline (n† 112) & 1065.02 & $1048 \cdot 66,1081 \cdot 38$ & 324.53 & $311 \cdot 15,337 \cdot 90$ & 735.45 & $720.83,750.06$ & 0.12 & $0 \cdot 10,0.14$ & 0.94 & $0.92,0.97$ & 0.82 & $0.80,0.84$ & 496.67 & $479.93,513 \cdot 42$ \\
\hline & Intervention $(n 16)$ & 963.47 & $919.05,1007.89$ & $286 \cdot 29$ & $251.55,321.03$ & 673.94 & $636.36,711.52$ & 0.09 & $0.04,0.13$ & 0.95 & $0.89,1.01$ & 0.84 & $0.79,0.89$ & 463.65 & $437.32,489.98$ \\
\hline \multirow[t]{2}{*}{ Healthy Choices School } & Baseline ( $(n 91)$ & 659.90 & $650.24,669.56$ & $242 \cdot 28$ & $234 \cdot 80,249 \cdot 76$ & 417.59 & $407 \cdot 05,428 \cdot 13$ & 0.10 & $0.08,0.12$ & 0.77 & $0.74,0.80$ & 0.71 & $0.69,0.73$ & $-\ddagger$ & - \\
\hline & Intervention ( $n 16)$ & 641.53 & $59 \cdot 68,686 \cdot 38$ & 273.29 & $252.99,293.60$ & $368 \cdot 24$ & $331 \cdot 30,405 \cdot 17$ & 0.13 & $0.08,0.18$ & 0.70 & $0.63,0.76$ & 0.67 & $0.62,0.72$ & $\stackrel{+}{+}$ & _- \\
\hline \multirow[t]{2}{*}{ Healthy Nudging School } & Baseline ( $(n 84)$ & 582.54 & $567.03,598.04$ & $225 \cdot 27$ & $217.01,233.53$ & $357 \cdot 11$ & $343.53,370 \cdot 68$ & 0.23 & $0.21,0.25$ & 0.87 & $0.84,0.90$ & 0.85 & 0.82 .0 .87 & $196 \cdot 11$ & $182 \cdot 38,209.84$ \\
\hline & Intervention ( $n 15)$ & 590.63 & $567.92,613.33$ & 239.81 & $217 \cdot 33,262 \cdot 30$ & 350.81 & $329.91,371.71$ & 0.24 & $0.19,0.29$ & 0.91 & $0.85,0.98$ & 0.86 & $0.81,0.92$ & 180.12 & $161 \cdot 15,199 \cdot 10$ \\
\hline Total number of days & & 332 & & 332 & & 332 & & 332 & & 332 & & 332 & & 225 & \\
\hline
\end{tabular}

†Number of days.

†Competitive foods sold at the Healthy Choices School and Comparison School were not compared since these items were completely removed from the Healthy Choices School during the intervention. 
selection of vegetables, fruit and milk. Consistent with the initial hypotheses, the number of entrées and share of entrées served with vegetables were higher when competitive foods were completely removed from the cafeteria. The implication of this finding is that it does not support the 'reactance' hypothesis that students will react negatively to competitive food removal and decrease meal participation $^{(9)}$. These results do, however, align with a limited number of prior studies assessing how the availability of competitive foods impacts meal participation. A pilot programme in San Francisco Unified School District during school year 2009-2010 found a substantial increase in meal participation in two high schools after a meal enhancement intervention which included removing competitive foods ${ }^{(19)}$. Other studies have found that enhanced local, state and federal regulation improving the nutritional quality of competitive foods also increases meal participation ${ }^{(18,30)}$. Additional studies are needed across a diverse array of school districts to further assess how competitive food removal influences meal participation.

It is noteworthy that the increase in meal participation in the Healthy Choices School was largely driven by students choosing to take more cold entrées. This is likely the result of the new, additional location for pre-made, portable sandwiches and salads. This finding suggests that students may have been selecting competitive foods before the intervention because they were convenient to carry, and these cold meal options fulfilled the same need. Future research could test the single intervention of adding a line for cold, portable meals. It is also possible that the additional lunch line reduced wait times for school meals; this is also an empirical question that could be tested. Another factor that may have contributed to the increased meal participation in the Healthy Choices School is that all three of the high schools in the study were closed campus (i.e. students were not able to leave campus to purchase other foods). Future studies could examine whether removing competitive foods in open campus schools is associated with similar increases in meal participation.

The number of daily entrées served also increased in the Healthy Nudging School, although the marketing strategies to promote milk and fruit were not associated with significant increases in students selecting those components with their school meals. This could be due to a ceiling effect; at baseline in the Healthy Nudging School, $85 \%$ of lunches included milk and $87 \%$ included a fruit serving, leaving little room for improvement. It is also possible that the nudging strategies used in the intervention were not salient enough to shift student selection of meal components. Notably, the nudging strategies did not appear to influence the sale of competitive foods. This may be because the strategies implemented were focused on increasing the appeal of the school meals, not specifically decreasing the accessibility of the competitive foods. 
One strength of the present study is that the three schools were very similar to each other and were randomly assigned to the three conditions. Some limitations should be noted. First, only three schools were enrolled in the study. A group-randomized trial where multiple schools are assigned to each intervention is needed to further examine these interventions. Second, the data reflect foods purchased or provided, not dietary intake, and we did not collect data on students bringing snacks to school. Future research can assess whether students are more likely to bring snacks from home or purchase more at stores on the way to or from school if they are not available in the school cafeteria. This line of inquiry is important given that a 2009 study in Philadelphia, PA found that foods purchased in corner stores contribute a significant amount of energy to urban schoolchildren's diet ${ }^{(31)}$. Third, the intervention was only four weeks long; longer-term follow-up of the changes observed when competitive foods are removed would be advantageous. Longer-term studies could also examine if there is a novelty effect of the marketing and nudging strategies, or the line with sandwiches and salads instead of competitive foods, that wears off after a period of time. To this point, Cohen et al. demonstrated that some cafeteria interventions do not appear to influence student consumption over the long term ${ }^{(32)}$. Fourth, milk and fruit were the only school meal components specifically marketed and nudged in the Healthy Nudging School. Future research could assess how nudging and marketing the vegetable side dishes that are sometimes part of the school meal impacts vegetables served and meal participation rates. Finally, the present study was conducted in schools where students are universally eligible for free school meals, so the findings may not be generalizable to higher-income populations.

\section{Conclusions}

Removing competitive foods from a high-school cafeteria was associated with a significant increase in meal participation and share of entrées served with vegetables. Although these findings are encouraging, larger studies are needed to determine how meal participation is affected by removing competitive foods. Cafeteria nudging and marketing strategies were also associated with higher school meal participation. However, contrary to the study hypothesis, there was not a decrease in competitive food sales. This suggests that an increase in meal participation may not necessarily be associated with a decrease in competitive food purchases. The implication of these findings is that additional strategies to reduce competitive food purchases are needed, since complete removal of these items may not be feasible for some schools.

\section{Acknowledgements}

Acknowledgements: The authors would like to acknowledge the cooperation of the Bridgeport, CT school system, the food-service director and cafeteria staff, and the principals of the three high schools where the study took place. Financial support: This research was funded by the Healthy Eating Research Program of the Robert Wood Johnson Foundation (ID number 70740). The Robert Wood Johnson Foundation had no role in the design, analysis or writing of this article. Conflict of interest: None. Authorship: K.E.H. conceptualized the idea and designed the study; K.E.H., M.R. and M.B.S. designed the interventions; M.R. oversaw the interventions onsite and collected data; R.B. carried out data cleaning, preparation, analyses and wrote the first and subsequent drafts of the manuscript. All authors reviewed and commented on subsequent drafts, including the final draft, of the manuscript. Ethics of buman subject participation: This research protocol was deemed exempt from the Yale University Institutional Review Board because only administrative data were used.

\section{Supplementary material}

To view supplementary material for this article, please visit https://doi.org/10.1017/S136898001900329X

\section{References}

1. Food and Nutrition Service, US Department of Agriculture (2013) National School Lunch Program Fact Sheet. Alexandria, VA: USDA.

2. Johnson DB, Podrabsky M, Rocha A et al. (2016) Effect of the Healthy Hunger-Free Kids Act on the nutritional quality of meals selected by students and school lunch participation rates. JAMA Pediatr 170, e153918.

3. Food and Nutrition Service, US Department of Agriculture (2013) Final Rule: National School Lunch Program and School Breakfast Program: Nutrition Standards for All Foods Sold in School as Required by Healthy, Hunger Free Kids Act of 2010. https://www.federalregister.gov/ documents/2016/07/29/2016-17227/national-school-lunchprogram-and-school-breakfast-program-nutrition-standardsfor-all-foods-sold-in (accessed November 2019).

4. Hennessy E, Oh A, Agurs-Collins T et al. (2014) State-level school competitive food and beverage laws are associated with children's weight status. J Sch Health 84, 609-616.

5. Thorndike AN, Sonnenberg LM, Riis J et al. (2012) A 2-phase labeling and choice architecture intervention to improve healthy food and beverage choices. Am J Public Health 102, 572-533.

6. Hanks AS, Just DR \& Wansink B (2013) Smarter lunchrooms can address new school lunchroom guidelines and childhood obesity. J Pediatr 162, 867-869.

7. Schwartz MB, Just DR, Chriqui JF et al. (2017) Appetite selfregulation: environmental and policy influences on eating behaviors. Obesity (Silver Spring) 25, Suppl. 1, S26-S38.

8. Gosliner W, Madsen KA, Woodward-Lopez G et al. (2011) Would students prefer to eat healthier foods at school? J Sch Health 81, 146-151.

9. Hanks AS, Just DR, Smith LE et al. (2012) Healthy convenience: nudging students toward healthier choices in the lunchroom. J Public Health 34, 370-376.

10. Johnson EJ, Shu SB, Dellaert BGC et al. (2012) Beyond nudges: tools of a choice architecture. Mark Lett 23, 487-504. 
11. Just DR, Wansink B, Gabrielyan G et al. (2017) How to make kids eat healthier in school cafeterias: an evidence from smarter lunchrooms program in North East US. FASEB J 31, 787.6.

12. Springer AE, Kelder SH, Byrd-Williams CE et al. (2013) Promoting energy-balance behaviors among ethnically diverse adolescents: overview and baseline findings of the central Texas CATCH Middle School Project. Health Educ Behav 40 , 559-570.

13. Greene K, Gabrielyan G, Brumberg A et al. (2016) Smarter lunchrooms randomized control trial: results from year 3 . J Nutr Educ Behav 48, issue 7, S119-S120.

14. Greene KN, Gabrielyan G, Just DR et al. (2017) Fruit-promoting smarter lunchrooms interventions: results from a cluster RCT. Am J Prev Med 52, 451-458.

15. Wharton CM, Long M \& Schwartz MB (2008) Changing nutrition standards in schools: the emerging impact on school revenue. J Sch Health 78, 245-251.

16. National Center for Chronic Disease Prevention and Health Promotion, Division of Adolescent and School Health (2011) Implementing Strong Nutrition Standards for Schools: Financial Implications. Atlanta, GA: Centers for Disease Control and Prevention.

17. Peart T, Kao J, Crawford PB et al. (2012) Does competitive food and beverage legislation hurt meal participation or revenues in high schools? Child Obes 8, 339-346.

18. Long MW, Henderson KE \& Schwartz MB (2010) Evaluating the impact of a Connecticut program to reduce availability of unhealthy competitive food in schools. $J$ Sch Health $\mathbf{8 0}$, 478-486.

19. Bhatia R, Jones P \& Reicker Z (2011) Competitive foods, discrimination, and participation in the National School Lunch Program. Am J Public Health 101, 1380-1386.

20. Gordon A, Crepinsek MK, Nogales R et al. (2007) School Nutrition Dietary Assessment Study-III. Volume I: School Foodservice, School Food Environment, and Meals Offered and Served. Princeton, NJ: Mathematica Policy Research, Inc.

21. Hanks AS, Just DR \& Wansink B (2012) Smarter Lunchrooms: Libertarian Paternalism Can Address New School Lunchroom Guidelines and Childhood Obesity. Rochester, NY: Social Science Research Network.
22. Lytle LA, Seifert S, Greenstein J et al. (2000) How do children's eating patterns and food choices change over time? Results from a cohort study. Am J Health Promot 14, 222-228.

23. Morton JF \& Guthrie JF (1998) Changes in children's total fat intakes and their food group sources of fat, 1989-91 versus 1994-95: implications for diet quality. Fam Econ Nutr Rev 11, 44-57.

24. Bureau of Health and Nutrition, Family Services and Adult Education (2011) Complying with Healthy Food Certification Under Section 10-215f of the Connecticut General Statutes. Middletown, CT: Connecticut State Department of Education.

25. Food and Nutrition Service, US Department of Agriculture (2019) National School Lunch Program | Community Eligibility Provision. https://www.fns.usda.gov/school-meals/ community-eligibility-provision (accessed November 2019).

26. Smarter Lunchrooms Movement: Nudging Kids to Eat Healthier (2017) The Smarter Lunchrooms Strategies. https://www.smarterlunchrooms.org/scorecard-tools/smarterlunchrooms-strategies (accessed November 2019).

27. Dimick JB \& Ryan AM (2014) Methods for evaluating changes in health care policy: the difference-in-differences approach. JAMA 312, 2401-2402.

28. Angrist JD \& Pischke J-S (2008) Mostly Harmless Econometrics: An Empiricist's Companion. Princeton, NJ: University Press.

29. Connecticut State Department of Education (n.d.) School District and School Data for Connecticut Schools. http:// edsight.ct.gov/SASPortal/main.do (accessed October 2018).

30. Chriqui JF, Pickel M \& Story M (2014) Influence of school competitive food and beverage policies on obesity, consumption, and availability: a systematic review. JAMA Pediatr $\mathbf{1 6 8}$, 279-286.

31. Borradaile KE, Sherman S, Veur SSV et al. (2009) Snacking in children: the role of urban corner stores. Pediatrics 124, 1293-1298.

32. Cohen JFW, Richardson SA, Cluggish SA et al. (2015) Effects of choice architecture and chef-enhanced meals on the selection and consumption of healthier school foods: a randomized clinical trial. JAMA Pediatr 169, 431-437. 